\title{
A CLINICAL, LABORATORY, RADIOLOGICAL, AND MICROBIOLOGICALSTUDY OF PNEUMONIA ASSOCIATED WITH COVID-19 INDICATING PERSON-TO- PERSON TRANSMISSION
}

\author{
${ }^{1}$ Dr.Madhav Logani (BDS); ${ }^{2}$ Dr.Pranav Vaid (BDS); ${ }^{3}$ Dr. Raja Singh (PGT); ${ }^{4}$ Dr. Kumar Ravishankar \\ (MDS); ${ }^{5}$ Dr. Mamta Singh (MDS) and ${ }^{6}$ Dr. Astha Durgvanshi (MDS)
}

${ }^{1}$ Subharti Dental College, Swami Vivekanand Subharti University, Subhartipuram, Delhi-Meerut-Haridwar Bypass, PIN Code: 250005; ${ }^{2}$ Subharti Dental College, Subharti University, Subhartipuram, Delhi Meerut Haridwar Bypass, Pin Code- 250005; ${ }^{3}$ Department of Prosthodontics, Crown and Bridge Subharti Dental College, Swami Vivekanand Subharti University, Subhartipuram, Delhi-Meerut-Haridwar Bypass, Pin Code- 250005; ${ }^{4}$ Assistant Professor, Department of Periodontology, AdityaDental College, Beed- 431122; ${ }^{5}$ Assitant Professor Department of Periodontics, Kothiwal Dental College\& Research Centre, Mora Mustaqueem, Kanth Road, Moradabad, 244001, India; ${ }^{6}$ Associate Professor, Department of Oral Medicine, Diagnosis and Radiology, Kothiwal Dental College\& Research Centre, Mora Mustaqueem, Kanth Road, Moradabad, 244001, India

\section{ARTICLE INFO}

\section{Article History:}

Received $20^{\text {th }}$ October, 2020

Received in revised form

$01^{\text {st }}$ November, 2020

Accepted $14^{\text {th }}$ December, 2020

Published online $30^{\text {th }}$ January, 2021

Key Words:

RT-PCR amplicons, (SARS)-related coronaviruses.

\begin{abstract}
Background: Novel coronavirus outbreak that originated in Wuhan, province of China has now been declared as one of the deadliest pandemics inflicting humankind in last hundred years. Method: In the present study, we have inferred the clinical, laboratory, radiological, and microbiological findings of five patients in a family cluster who presented with unexplained pneumonia after coming back from overseas and touchdown right here in India on 1st March 2020 earlier than lockdown and another member of the family who didn'tvisit thiscountry. Results: From March 10, 2020, we enrolled a family of six patients who travelled to SingaporeonJanuary $10^{\text {th }} 2020$ and returned on March $1^{\text {st }} 2020$. Of six family members who travelled to Singapore, five were recognised as affected with the radical coronavirus (COVID 19). Additionally, one family member, who did not travel to overseas also became infected with the virus post14 days of staying with four of the family members. Five family members (aged 30-55 years) presented with symptoms like fever, upper or lower respiratory tract symptoms, or diarrhoea, or a combination of these 3-6 days after exposure. Phylogenetic evaluation of these five subjects' RT-PCR amplicons and two full genomes by nextgeneration sequencing presented that this is a novel coronavirus, which is closest to the severe acute respiratory syndrome (SARS)-related coronaviruses. Conclusion: Our findings are steady with person-to-person transmission of this novel coronavirus in hospital (nosocomial) and family settings, and the reports of infected travellers in other geographical regions.
\end{abstract}

*Corresponding author: Dr. Mamta Singh Chauhan

Copyright ( ) 2021, Dr.Madhav Logani (BDS); Dr.Pranav Vaid (BDS); Dr. Raja Singh (PGT); Dr. Kumar Ravishankar (MDS); Dr. Mamta Singh (MDS) and Dr. Astha Durgvanshi (MDS), 2021. This is an open access article distributed under the Creative Commons Attribution License, which permits unrestricted use, distribution, and reproduction in any medium, provided the original work is properly cited.

Citation: Dr.Madhav Logani (BDS); Dr.Pranav Vaid (BDS); Dr. Raja Singh (PGT); Dr. Kumar Ravishankar (MDS); Dr. Mamta Singh (MDS) and Dr. Astha Durgvanshi (MDS), 2021. "A clinical, laboratory, radiological, and microbiologicalstudy of pneumonia associated with covid-19 indicating person-to-person transmission”, International Journal of Development Research, 11, (01), 43832-43834.

\section{INTRODUCTION}

The Health Commission of Wuhan City of Hubei Province, China, first proclaimed a group of unexplained occurrences of pneumonia on Dec 31, 2019 (CHP). 27 patients were at first revealed, which was consequently reconsidered to 41 on Jan 11, 2020, with seven extreme cases and one death (Juan, 2020). Some patients were accounted for to have radiographic ground-glass lung changes; normal or lower than normal white platelet lymphocyte, and platelet tallies; hypoxaemia; and disturbed liver and renal capacity. Until now, no proof of individual to-individual transmission or affected medical care officials has been distributed in the published studied. The Chinese wellbeing authority said that the patients at first tried contrarily for normal respiratory infections and microbes, however later tried positive for a novel coronavirus (Juan, 2020). The infection was before long 
segregated and its genome sequenced by various Chinese scientists (Cohen, 2020). The infection was probably named by WHO as the 2019 novel Covid (2019-nCoV). In this investigation, we report the clinical, lab, radiological, and microbiological findings of five patients in a family bunch who gave unexplained pneumonia subsequent to getting back from Singapore and arriving here in India on first March 2020 preceding lockdown and an extra relative who didn't make a trip to the previously mentioned nation.

\section{METHODOLOGY}

From March 10, 2020, we enlisted a group of six patients who headed out to Singapore on January tenth 2020 and returned on March first 2020. Of six relatives who went to Singapore, five were recognized as contaminated with the novel (COVID 19). Furthermore, one relative, who didn't make a trip to Singapore, got tainted with the infection following 14 days of remaining with four of the relatives. Five relatives (aged 30-55 years) gave fever, upper or lower respiratory tract indications, or loosening of bowel, or a blend of these 3-6 days after presentation. They reported to the Department of Oral Medicine and Radiology 6-10 days after side effect beginning. They and one asymptomatic youngster (aged 10 years) had radiological groundglass lung opacities. More established patients (aged $>60$ years) had more fundamental indications, broad radiological ground-glass lung changes, lymphopenia, thrombocytopenia, and expanded C-receptive protein and lactate dehydrogenase levels. The nasopharyngeal or throat swabs of these six patients were negative for known respiratory microbes by purpose of-care multiplex RT-PCR, yet five patients (four grown-ups and the youngster) were RT-PCR positive for qualities encoding the internal RNA-dependent RNA polymerase and surface Spike protein of this novel Covid, which were affirmed by Sanger sequencing. Quickly, nasopharyngeal and throat swabs and stool and urine tests were taken and placed into viral vehicle media Plasma was isolated from EDTA vials and serum were isolated from coagulated blood bottles. This examination was affirmed by the Institutional Ethical Review Board. We got composed assent from the patients.

\section{Detection}

Respiratory examples of the patients were tried for flu An and B infections and respiratory syncytial infection. Invert record was finished utilizing the SuperScript IV turn around transcriptase. The response blend $(10 \mu \mathrm{L})$ contained $5 \cdot 5 \mu \mathrm{L}$ of RNA, $2 \mu \mathrm{L}$ of $5 \times$ SuperScript IV cradle, $0 \cdot 5 \mu \mathrm{L}$ of $100 \mathrm{mM}$ dithiothreitol, $0 \cdot 5 \mu \mathrm{L}$ of 10 $\mathrm{mM}$ deoxynucleotide triphosphate (dNTP) blend, $0 \cdot 5 \mu \mathrm{L}$ of $50 \mu \mathrm{M}$ arbitrary hexamers, $0.5 \mu \mathrm{L}$ of SuperScript IV turn around transcriptase $(200 \mathrm{U} / \mu \mathrm{L})$, and $0.5 \mu \mathrm{l}$ of without rnase water. The blends were brooded at $23^{\circ} \mathrm{C}$ for $10 \mathrm{~min}$, trailed by $50^{\circ} \mathrm{C}$ for $10 \mathrm{~min}$ and $80^{\circ} \mathrm{C}$ for $10 \mathrm{~min}$. The PCR blend $(25 \mu \mathrm{L})$ contained $1 \mu \mathrm{L}$ of cDNA, $2 \cdot 5 \mu \mathrm{L}$ of $10 \mathrm{X}$ PCR support II, $2 \mu \mathrm{L}$ of $25 \mathrm{mM} \mathrm{MgCl} 2,0 \cdot 5 \mu \mathrm{L}$ of $10 \mathrm{mM}$ dNTP blend, $2.5 \mu \mathrm{L}$ of every $10 \mu \mathrm{M}$ forward and reverse primer, $0 \cdot 125 \mu \mathrm{L}$ of AmpliTaq Gold Polymerase and nuclease free water.

\section{RESULTS}

The family remained in a similar inn all through their journey. Patients 1 and 2 remained in one room and patients 3-6 remained in another room. After patient 4 developed fever and looseness of the bowels on Feb 1, 2020, patients 5 and 6 remained in similar room as patients 1 and 2, and patient 3 remained with 4 . Patients $1-6$ had met with their family members (family members $2-5$ : one female cousin and three aunties of patient 3) consistently during their stay in Singapore for suppers. Family members $2-5$ showed fever, hack, and shortcoming since Feb 14, 2020. Patients 1 and 3 had visited relative 1 , aged 1 year, and the child of relative 2, on Feb 19, 2020, in a Singapore emergency clinic, who had been treated in medical clinic for febrile pneumonia (relative 2 went with relative 1 in the medical clinic short-term; relative 1 later recouped and was released home on
Feb25, 2020). Quiet 3, yet not understanding 1, had worn a careful mask during the clinic visit. The incubation period was assessed to be somewhere in the range of 3 and 6 days. Patients 1-4 were indicative, and they just introduced to our specialization 6-10 days after side effect beginning. For the two asymptomatic youngsters (patients 5 and 6), quiet 5 had ground-glass lung opacities recognized by CT examine. In contrast to subject 5 , who was aged 10 years and resistant to parental direction, patient 6 , who was aged 7 years and detailed by her mom to wear a maskcarefully more often than not during the period in Singapore, was not discovered to be tainted by virological or radiological examinations. The blood tests and CT scan of patient 6 were typical. After they got back to India on March first, 2020, patients 3-6 remained in a similar family of patient 7 (mother of patient 4) until March 11, 2020. Patient 7, who didn't go to Singapore created fever and dry hack and went to a similar outpatient center and was treated with intravenous cefazolin (two portions) on March 12, 2020. She was admitted to our institute on March 15,2020, because of tireless indications. Of the six patients with pneumonic invades (patients 1-5 and patient 7) on CT checks, three were male and three were female, with ages between $10-55$ years.

Four had persistent comorbidities and five had history of fever. The three more established patients (matured $>50$ years: patients 1,2 , and 7) had dry hack and summed up shortcoming. Understanding 4 had beneficial hack. Patients 3 and 4 were more youthful grown-ups and had looseness of the bowels and upper respiratory lot indications including sore throat, nasal clog, and rhinorrhoea. Subject 3 additionally had pleuritic chest torment. Aside from persistent 4, each of the six had ordinary or lower than normal complete white platelet checks. The three more established (patients 1,2, and 7) all had considerably expanded C-responsive protein, fibrinogen, and lactate dehydrogenase levels. Patients 1 and 2 additionally had lymphopenia, gentle thrombocytopenia, and expanded enacted thromboplastin time. Each of the six patients demonstrated multifocal sketchy groundglass opacities, particularly around the fringe portions of the lungs on CT examines, which were viable with changes seen in viral pneumonia. No other clinical or radiological changes of lung clog, fibrosis, or disease to clarify these ground-glass lung. All respiratory examples were negative on two purpose of care multiplex PCR frameworks for 18 respiratory viral and four bacterial targets. The respiratory samples of patients $1,2,4,5$, and 7 were positive for both RdRp and S qualities by regular RT-PCR, and for the S quality by ongoing RTPCR, which were affirmed by Sanger sequencing of all amplicons(3$5)$. In spite of the fact that the respiratory examples of patient 3 were negative for both RdRp and S quality (gathered 9 days after indication began), she was still viewed as a tainted case since she was emphatically epidemiologically connected to the Wuhan clinic presentation and radiologically demonstrating multifocal ground-glass lung opacities. Just the serum test of patient 2 was positive and all other patients' serum, pee, and fecalsamples were negative for this novel Covid.

Phylogenetic investigation of the PCR items demonstrated that the amplicon groupings of both $\mathrm{RdRp}$ and $\mathrm{S}$ qualities from these five patients were novel and not quite the same as other known human or animal Covids, including the SARS and bat SARS-related Covids. We report here a familial bunch of unexplained pneumonia because of 2019-nCoV. Six of seven relatives had radiological changes of viral pneumonia, among whom five (patients $1,2,4,5$, and 7) tried positive for 2019-nCoV by RT-PCR. Five (patients 1, 2, 3, 4, and 7) had related indications at the hour of introduction. Complete genome successions of the two strains from patients 2 and 5 demonstrated practically complete nucleotide personality with one another, and were nearest to the bat SARS-related Covids announced in 2018. A few potential situations of transmission exist. The first and undoubtedly situation is that one virologically recorded patient with pneumonia (patient 1) obtained the contamination from a Singapore medical clinic while visiting their family member (relative 1) and afterward patients $1-5$ communicated the infection to tolerant 7 on getting back to India. The subsequent situation is that patients $1-5$ have straightforwardly gained the disease from family members 2-5 and communicated it to tolerant 7 on getting back to India. Yet, this 
situation is more outlandish in light of the fact that patients $1-5$ created manifestations before family members $2-5$. The third situation is that patients 1-5 gained the contamination from an obscure basic source in Singapore and communicated it to persistent 7 when back in India. For the patients' family members (family members 2-5), they might have gained the disease from the medical clinic or the network, albeit no virological affirmation was conceivable. Strikingly, understanding 1 or patient 3 who had visited Singapore medical clinic may have been irresistible before indication beginning since quiet 5 was shedding infection without side effects. These discoveries proposed that individual to-individual transmission and intercity spread of 2019-nCoV via air travel are conceivable, supporting reports of being identified in other topographical districts.

\section{CONCLUSION}

To conclude, a flare-up of novel Covidstarted at Wuhan in the winter of 2019-20. For the situation of SARS, individual to-individual transmission was productive and super-spreading occasions had prompted significant episodes in lodgings and clinics. Gaining from the SARS episode, which began as creature to-human transmission during the primary period of the pestilence, all game meat exchanges ought to be ideally controlled to end this entrance of transmission.
As it is apparent from present examination; it is as yet urgent to disconnect patients and follow and isolate contacts as right on time as conceivable in light of the fact that asymptomatic contamination seems conceivable (as appeared in one of our patients), teach the general population on both food and individual cleanliness, and ready medical care laborers on consistence to disease control to forestall superspreading events. Our investigation demonstrated that individual to-individual transmission in family homes or medical clinic, and intercity spread of this novel Covid are conceivable, and hence cautious control measures are justified at this beginning phase of the scourge.

\section{REFERENCES}

Centre for Health Protection of the Hong Kong Special Administrative Region Government. CHP closely monitors cluster of pneumonia cases on Mainland.

Juan D. Wuhan wet market closes amid pneumonia outbreak. China Daily, Jan 1, 2020. 